\title{
Oxide vs. Non-oxide Cathode Materials for Aqueous Zn Batteries: An Insight into the Charge Storage Mechanism and Consequences Thereof
}

Pascal Oberholzer, Elena Tervoort, Assil Bouzid, Alfredo Pasquarello, and Dipan

Kundu*

Pascal Oberholzer, Dr. Elena Tervoort, Dr. Dipan Kundu

Multifunctional Materials

Department of Materials

ETH Zurich

Vladimir Prelog Weg 5

8093 Zurich

Switzerland

Email: dipan.kundu@mat.ethz.ch

Dr. Assil Bouzid, Prof. Dr. Alfredo Pasquarello

Chaire de Simulation à l'Échelle Atomique (CSEA)

École Polytechnique Fédérale de Lausanne (EPFL)

CH-1015 Lausanne, Switzerland

Keywords: Aqueous $\mathrm{Zn}$-ion batteries, charge storage mechanism, oxide $v$ s. non-oxide hosts, $\mathrm{Zn}^{2+}$ $v s$. proton intercalation, layered double hydroxide precipitation, consequence of proton intercalation

\begin{abstract}
Aqueous $\mathrm{Zn}$-ion batteries, which are being proposed as large scale energy storage solutions due to their unparalleled safety and cost advantage, are comprised of a positive host (cathode) material, a metallic zinc anode, and a mildly acidic aqueous electrolyte ( $\mathrm{pH} \sim 3-7)$. Typically, the charge storage mechanism is believed to be reversible $\mathrm{Zn}^{2+}$ (de)intercalation in the cathode host, with the exception of $\alpha-\mathrm{MnO}_{2}$, for which multiple vastly different and contradicting mechanisms have been proposed. However, our present study, combining electrochemical, operando X-ray diffraction (XRD), electron microscopy in conjunction with energy dispersive X-ray spectroscopy (EDX), and in situ $\mathrm{pH}$ evolution analyses on two oxide hosts - tunneled $\alpha-\mathrm{MnO}_{2}$ and layered $\mathrm{V}_{3} \mathrm{O}_{7} \cdot \mathrm{H}_{2} \mathrm{O}$ vis-à-vis two non-oxide hosts - layered $\mathrm{VS}_{2}$ and tunneled $\mathrm{Zn}_{3}\left[\mathrm{Fe}(\mathrm{CN})_{6}\right]_{2}$, suggests that oxides and non-oxides follow two dissimilar charge storage mechanisms. While the oxides behave as dominant proton intercalation materials, the non-oxides undergo exclusive zinc intercalation. Stabilization of the $\mathrm{H}^{+}$on the hydroxyl terminated oxide surface is revealed to facilitate the proton
\end{abstract}


intercalation by a preliminary molecular dynamics simulation study. Proton intercalation for both oxides leads to the precipitation of layered double hydroxide $(\mathrm{LDH})-\mathrm{Zn}_{4} \mathrm{SO}_{4}(\mathrm{OH})_{6} \cdot 5 \mathrm{H}_{2} \mathrm{O}$ with $\mathrm{ZnSO}_{4} / \mathrm{H}_{2} \mathrm{O}$ electrolyte and a triflate anion $\left(\mathrm{CF}_{3} \mathrm{SO}_{3}{ }^{-}\right)$based $\mathrm{LDH}$ with $\mathrm{Zn}\left(\mathrm{SO}_{3} \mathrm{CF}_{3}\right)_{2} / \mathrm{H}_{2} \mathrm{O}$ electrolyte - on the electrode surface. The LDH precipitation buffers the $\mathrm{pH}$ of the electrolytes to a mildly acidic value, sustaining the proton intercalation to deliver large specific capacities for the oxides. Moreover, we also show that the stability of the LDH precipitate is crucial for the rechargeability of the oxide cathodes, revealing a critical link between the charge storage mechanism and the performance of the oxide hosts in aqueous zinc batteries.

\section{INTRODUCTION}

A future energy generation mix with a high share of intermittent renewables requires advancement in large-scale energy storage to balance demand and supply, while maintaining the reliability and power quality of the grid. ${ }^{1}$ Li-ion batteries (LIBs), with its high energy and power densities, seem like a good fit having an established foothold in the marketplace. ${ }^{2}$ Yet, the advantages that made them ubiquitous in portable applications do not necessarily hold for large-scale deployment, where cost, safety, and lifetime are more of a concern than energy and power densities. ${ }^{3}$ Aqueous rechargeable batteries, which utilize low-cost and safe water-based electrolytes and involve simple assembly conditions, offer promising alternatives. ${ }^{3,4,5}$ Among these candidates, Zn based systems are particularly attractive owing to zinc's low-cost, abundance, environmental benignity, and high volumetric capacity of $5854 \mathrm{mAh} \mathrm{cm}^{-3}{ }^{6,7}$ More importantly, a suitable redox potential $(-0.76 \mathrm{~V}$ vs. the Standard Hydrogen Electrode (SHE)) and suppression of hydrogen evolution on zinc, endows aqueous zinc batteries (AZBs) a kinetic voltage window exceeding $2 \mathrm{~V}$. $^{7}$

Yet, high charge density of $\mathrm{Zn}^{2+}$ and consequent sluggish solid-state diffusion inside inorganic frameworks limit the choice of cathode (positive) host materials. ${ }^{8}$ So far reported hosts are primarily oxides - e.g., $\alpha-\mathrm{MnO}_{2},{ }^{9} \lambda-\mathrm{MnO}_{2},{ }^{10} \mathrm{Mg}_{1.8} \mathrm{Mn}_{6} \mathrm{O}_{12},{ }^{11} \mathrm{~V}_{3} \mathrm{O}_{7} \cdot \mathrm{H}_{2} \mathrm{O},{ }^{12} \mathrm{Zn}_{0.25} \mathrm{~V}_{2} \mathrm{O}_{5} \cdot \mathrm{nH}_{2} \mathrm{O},{ }^{13}$ $\mathrm{LiV}_{3} \mathrm{O}_{8},{ }^{14} \mathrm{Zn}_{3} \mathrm{~V}_{2} \mathrm{O}_{7}(\mathrm{OH})_{2} \cdot 2 \mathrm{H}_{2} \mathrm{O},{ }^{15}$ etc., beside only a few non-oxides like layered $\mathrm{VS}_{2}{ }^{16}$ and prussian blue analogues $-\mathrm{Zn}_{3}\left[\mathrm{Fe}(\mathrm{CN})_{6}\right]_{2}{ }^{17}$ and $\mathrm{KCuFe}(\mathrm{CN})_{6} \cdot{ }^{18}$ All these materials are either layer or tunnel structured with wide ion diffusion paths, and generally nanostructured materials are employed to tackle the diffusion limitation. ${ }^{9-18}$ However, the nature of the electrochemical charge storage mechanism, which can influence the reversibility and long-term cyclability of these materials, is not unequivocally clear. Besides, the complexities that can arise due to the use of 
aqueous electrolytes, specifically, proton co-intercalation ${ }^{19}$ and consequent side reactions, ${ }^{20,21}$ are rarely addressed. The formation of the layered double hydroxide (LDH) type insulating corrosion product - $\mathrm{Zn}_{4} \mathrm{SO}_{4}(\mathrm{OH})_{6} \cdot \mathrm{nH}_{2} \mathrm{O}$, observed with some oxide host materials, ${ }^{13,15,19}$ have been linked to the $\mathrm{pH}$ increase of the electrolyte, ${ }^{22}$ but circumstances leading to its formation, and its influence on the reversible operation of the zinc batteries remain ambiguous.

Therefore, in this work, we attempt to elucidate the nature of electrochemical reactions involved with the oxide materials $\alpha-\mathrm{MnO}_{2}$ and $\mathrm{V}_{3} \mathrm{O}_{7} \cdot \mathrm{H}_{2} \mathrm{O}$ vis-à-vis the non-oxides $\mathrm{VS}_{2}$ and $\mathrm{Zn}_{3}\left[\mathrm{Fe}(\mathrm{CN})_{6}\right]_{2}(\mathrm{ZnHCF})$ in $\mathrm{ZnSO}_{4}$ and $\mathrm{Zn}\left(\mathrm{OSO}_{2} \mathrm{CF}_{3}\right)_{2}$ (aka, $\left.\mathrm{Zn}(\mathrm{OTf})_{2}\right)$ based mildly acidic aqueous electrolytes $(\mathrm{pH} \sim 4)$. Since it is practically impossible to study all reported oxides majority of which are layered vanadium oxides - we carefully selected hosts representing the main two structure type (layered: $\mathrm{V}_{3} \mathrm{O}_{7} \cdot \mathrm{H}_{2} \mathrm{O}$ and $\mathrm{VS}_{2}$; tunnelled: $\alpha-\mathrm{MnO}_{2}$ and $\mathrm{ZnHCF}$ ) reported for $\mathrm{Zn}^{2+}$ storage. Strikingly, the two categories of materials display distinctly different charge storage mechanism, as revealed by combining operando XRD, SEM, STEM/EDS, galvanostatic cycling, and in situ $\mathrm{pH}$ measurements during cell cycling. While reversible proton (de)intercalation is found to be the dominant process for both oxides, non-oxides exhibit exclusively $\mathrm{Zn}^{2+}$ storage electrochemistry. A preliminary molecular dynamics simulations of $\mathrm{V}_{3} \mathrm{O}_{7} \cdot \mathrm{H}_{2} \mathrm{O}$ disclose a surface hydroxyl group mediated reconstruction process, stabilizing $\mathrm{H}^{+}$at the electrode/electrolyte interface, which seems to facilitate the $\mathrm{H}^{+}$transfer across the interface. Intercalation/release of $\mathrm{H}^{+}$ by the oxides leads to the precipitation/dissolution of $\mathrm{Zn}_{4} \mathrm{SO}_{4}(\mathrm{OH})_{6} \cdot 5 \mathrm{H}_{2} \mathrm{O}$ (in $\mathrm{ZnSO}_{4}$ electrolyte) at the electrode surface, which in turn buffers the interfacial and bulk electrolyte $\mathrm{pH}$ to sustain the $\mathrm{H}^{+}$(de)intercalation mechanism. Use of $\mathrm{Zn}(\mathrm{OTf})_{2}$ electrolyte also results in an unpresedented LDH phase involving the triflate anion, but only for the oxides. Interestingly, formation and presence of the $\mathrm{LDH}$ at the electrode is found to be essential for meaningful charge storage capacities and rechargeability of the system. These findings shed light on the complex charge storage mechanism in AZBs, and demonstrate the critical influence of $\mathrm{LDH}$ precipitation on the reversible operation of the oxide host materials.

\section{EXPERIMENTAL SECTION}

All host materials under investigation were synthesized following earlier reports by hydrothermal $\left(\alpha-\mathrm{MnO}_{2},{ }^{23} \mathrm{~V}_{3} \mathrm{O}_{7} \cdot \mathrm{H}_{2} \mathrm{O},{ }^{12} \mathrm{VS}_{2}{ }^{16}\right)$ or co-precipitation $\left(\mathrm{ZnHCF}^{17}\right)$ methods (see supplementary information (SI) for details and Figure S1 and S2 for the characterizations of synthesized materials). Cathode slurries were prepared by thoroughly mixing the as-synthesized active 
materials with carbon (Super P Carbon, TIMCAL) and water-based binder (3 wt\% carboxymethylcellulose (CMC) and $2 \mathrm{wt} \%$ styrene butadiene rubber (SBR)) in a 70:25:5 solid mass ratio with the addition of deionized water. The as-prepared, smooth slurries were brushed onto graphite foil ( $1 \mathrm{~cm}^{2}$ area, $0.254 \mathrm{~mm}$ thickness; Alfa Aesar, 99.8\%) or, in the case of operando cells, onto a glassy carbon disc $\left(0.785 \mathrm{~cm}^{2}\right.$ area, $50 \mu \mathrm{m}$ thickness $)$ and were subsequently dried under vacuum (12 h). A slightly different approach was used with $\mathrm{V}_{3} \mathrm{O}_{7} \cdot \mathrm{H}_{2} \mathrm{O}$, for which the active material was dispersed together with carbon (see above) and a dispersion of CMC/SBR (2:1) in water in a 70:27:3 solid mass ratio. The resulting homogeneous dispersion was filtered through a PVDF membrane (Durapore, Merck Millipore Ltd.), dried at $60^{\circ} \mathrm{C}$, and punched into $1 \mathrm{~cm}^{2}$ coins. In all cases the resulting electrodes had a typical loading of $3-5 \mathrm{mg} \mathrm{cm}^{-2}$.

Electrochemical measurements were performed in 2-electrode Swagelok type cells with titanium current collectors, and a homemade cell for operando experiments, on a VMP3 (Biologic) potentiostat/galvanostat. The cathodes were cycled at room temperature $\left(22 \pm 1{ }^{\circ} \mathrm{C}\right)$ against a metallic zinc coin anode with either a $1 \mathrm{M}$ aqueous solution of zinc sulfate $\left(\mathrm{ZnSO}_{4}, \mathrm{Acros}\right.$ Organics, $99.5 \%$ ) with a $\mathrm{pH}$ of 4.14 or a $2 \mathrm{M}$ aqueous solution of zinc trifluoromethanesulfonate $\left(\mathrm{Zn}(\mathrm{OTf})_{2}\right.$, Alfa Aesar, 98\%) with a pH of 4.25. For comparison, cells with $1 \mathrm{M} \mathrm{Li}_{2} \mathrm{SO}_{4}\left(\mathrm{Merck}_{\text {, }}\right.$ for analysis) and $1 \mathrm{M} \mathrm{MgSO}_{4}$ (Merck, for analysis) were prepared, adjusting the electrolyte $\mathrm{pH}$ to 4.1 by adding dilute sulfuric acid (Sigma-Aldrich, puriss.). Two glass fiber paper of $260 \mu \mathrm{m}$ thickness (Whatman ${ }^{\mathrm{TM}}$ glass microfiber filters, GF/A grade) served as the separator. If not otherwise mentioned, the cells were cycled within the respective potential window reported in literature $^{14,17,19,21}$ at a current rate of $\mathrm{C} / 5$, corresponding to the discharge/charge in $5 \mathrm{~h}(1 \mathrm{C}=1 \mathrm{~h}$ discharge/charge) according to the theoretical capacity of the respective active material. Specific capacity values were calculated with respect to the mass of the active cathode materials.

Powder X-ray diffraction was conducted on a PANalytical Empyrean diffractometer in Bragg-Brentano geometry using $\mathrm{Cu}-\mathrm{K} \alpha$ radiation $(\lambda=1.5405 \AA)$ and a PIXcel detector with a Ni $\mathrm{K}_{\beta}$ filter. For the operando XRD experiments, a homemade and hermetic two-electrode cell was used (see Figure S3 for details). The diffraction data was collected in the reflection mode from $5^{\circ}$ to $60^{\circ}(2 \theta)$ with a collection time of $15 \mathrm{~min}$. The scanning electron microscopy (SEM) studies were performed on a Carl Zeiss Leo 1530 scanning electron microscope, equipped with an energy dispersive X-ray spectroscopy (EDX) attachment. Electrochemically cycled electrodes were profusely washed with water to remove any electrolyte salt and dried under vacuum prior to SEM- 
EDX analysis. A thin layer of platinum ( $\mathrm{Pt} ; 5 \mathrm{~nm})$ was sputtered on the samples to avoid sample charging under electron beam. The transmission electron microscopy (TEM) in both TEM and scanning (STEM) modes was done on a FEI Talos F 200X, operated at $200 \mathrm{kV}$. STEM analyses were carried out with a high angle annular dark field detector (HAADF STEM) and were accompanied by the high-resolution energy dispersive spectroscopy (EDS) using the SuperX integrated EDS-system with four silicon drift detectors (SDDs). The EDS-STEM analyses were performed with a probe size of $0.5 \mathrm{~nm}$. Cycled electrodes were first thoroughly washed with deionized water and then dispersed in isopropanol by untrasonication. A drop of the dispersion was applied on a carbon coated copper grid for TEM-STEM analyses.

For the zeta-potential measurement, aqueous dispersions of $1 \mathrm{wt} \%$ of $\alpha-\mathrm{MnO}_{2}, \mathrm{~V}_{3} \mathrm{O}_{7} \cdot \mathrm{H}_{2} \mathrm{O}, \mathrm{VS}_{2}$ and $\mathrm{Zn}_{3}\left[\mathrm{Fe}(\mathrm{CN})_{6}\right]_{2}$ in $1 \mathrm{M} \mathrm{ZnSO}_{4}$ were prepared. The zeta-potential and $\mathrm{pH}$ measurement was performed with an electroacoustic zeta-potential probe (DT-310, Dispersion Technology Inc.). The in-situ $\mathrm{pH}$ measurement was conducted in a T-shaped 3-electrode cell. A pH meter (913 pH meter, Metrohm) inserted at the top end of the cell allowed the measurement of the bulk pH values during the galvanostatic cycling with a single channel potentiostat (SP-150, BioLogic Science Instruments) (see SI for details. To measure the $\mathrm{pH}$ of precipitation of the sulfate and triflate containing LDHs ex-situ, a dilute aqueous solution of $\mathrm{NaOH}$ was slowly added to the respective electrolyte solution while monitoring the $\mathrm{pH}$ evolution with a $\mathrm{pH}$ meter.

\section{RESULTS AND DISCUSSION}

Operando XRD study - probing the formation of layered double hydroxides (LDH). The nature of the electrochemical charge storage behavior of the two categories of host materials, i.e., oxides $-\alpha-\mathrm{MnO}_{2}$ and $\mathrm{V}_{3} \mathrm{O}_{7} \cdot \mathrm{H}_{2} \mathrm{O}$ and non-oxides $-\mathrm{VS}_{2}$ and $\mathrm{Zn}_{3}\left[\mathrm{Fe}(\mathrm{CN})_{6}\right]_{2}(\mathrm{ZnHCF})$ was elucidated by operando X-ray diffraction (XRD), which sheds light on the relation between electrochemistry and phase evolution of the host materials. It must be noted that the ion (de)intercalation in these materials is accompanied by reduction/oxidation at the transition metal centers; e.g., in $\alpha-\mathrm{MnO}_{2}$, the Mn switches between 4+ and 3+ redox states during electrochemical cycling.

Figures 1a and $\mathbf{b}$ show the phase evolution of $\alpha-\mathrm{MnO}_{2}$ for the first discharge-charge cycle. During discharge (reduction), the diffraction peaks of the $\alpha-\mathrm{MnO}_{2}$ shift to lower angles, corresponding to an expansion of the tunnel diameter by $\sim 0.3 \%$ (see Figure $\mathbf{S 4}$ for the crystal structure) at full discharge, which reverses upon charging (oxidation). In agreement with previous 

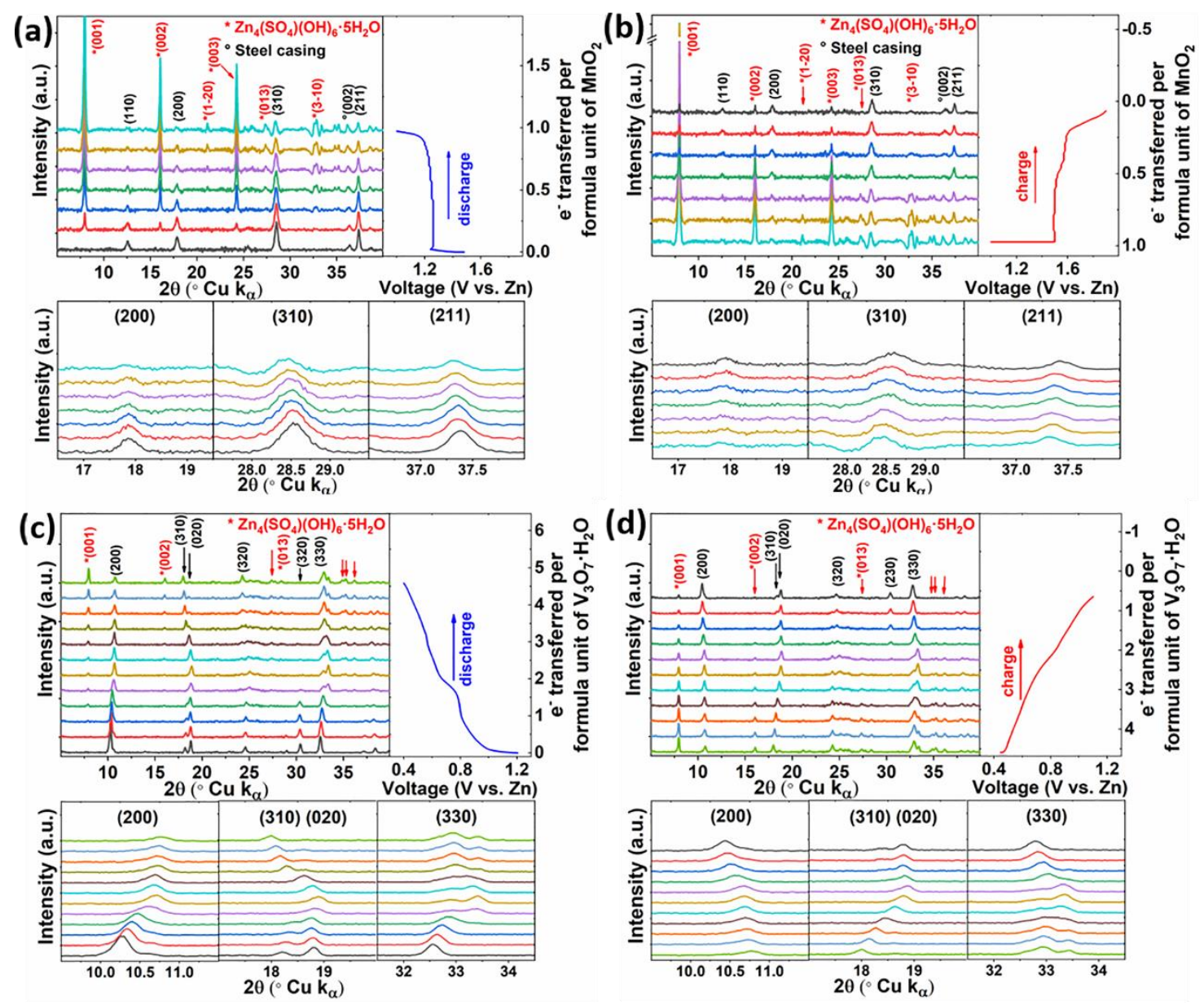

Figure 1. The Operando XRD study of a $\alpha-\mathrm{MnO}_{2}\left|\mathrm{ZnSO}_{4}\right| \mathrm{Zn}$ cell (a and b) and a $\mathrm{V}_{3} \mathrm{O}_{7} \cdot \mathrm{H}_{2} \mathrm{O}\left|\mathrm{ZnSO} \mathrm{Zn}_{4}\right| \mathrm{Zn}$ cell (c and d) at a (dis-)charge rate of C/5. Upper panel: XRD patterns (left) at different depths of discharge (a and c) and charge (b and d) along with the voltage-electron capacity profile (right); the diffraction peaks of the host material and the LDH precipitate are marked with black and red arrows, respectively. Lower panel: magnification of the main XRD plot.

studies, ${ }^{12,15}$ additional diffraction peaks emerge during discharge, which could be indexed to anorthic $\mathrm{Zn}_{4} \mathrm{SO}_{4}(\mathrm{OH})_{6} \cdot 5 \mathrm{H}_{2} \mathrm{O}$ - a layered double hydroxide (LDH) - with the space group $P-1$ (ICDD 39-0688). The process of LDH formation is almost completely reversible, as indicated by the near disappearance of LDH peaks upon charging. The exact mechanism and consequences of the LDH formation will be discussed in more detail at a later stage. The second oxide under investigation, $\mathrm{V}_{3} \mathrm{O}_{7} \cdot \mathrm{H}_{2} \mathrm{O}$, exhibits two distinct phase evolution regimes(Figure 1c and d), the transition taking place around $0.75 \mathrm{~V}$ vs. Zn after a transfer of $\sim 1.8 \mathrm{e}^{-}$per formula unit of the host. In the higher voltage regime (open circuit voltage/1.3 - 0.75 V), the interplanar ((200) planes) distance of layered $\mathrm{V}_{3} \mathrm{O}_{7} \cdot \mathrm{H}_{2} \mathrm{O}$ contracts by $\sim 0.676 \AA$ upon discharge, indicating a strong screening of the electrostatic repulsion between the negatively charged oxide layers by the intercalating 
cations. The movement of the diffraction peaks stops (200) or even reverses (310), (330) in the low voltage regime $(0.75-0.4 \mathrm{~V})$, while, analogous to $\alpha-\mathrm{MnO}_{2}$ the strong diffraction signals of $\mathrm{Zn}_{4} \mathrm{SO}_{4}(\mathrm{OH})_{6} \cdot 5 \mathrm{H}_{2} \mathrm{O}$ is observed. A reverse evolution occurs during charge, but the interplanar distance (200) remains contracted by $\sim 0.262 \AA$ at the end of charge, due to the retention of cations in the structure equivalent to $\sim 0.6 \mathrm{e}^{-}$per formula unit of the oxide host. Similar structural evolution is observed for both $\alpha-\mathrm{MnO}_{2}$ and $\mathrm{V}_{3} \mathrm{O}_{7} \cdot \mathrm{H}_{2} \mathrm{O}$ in $2 \mathrm{M} \mathrm{Zn}(\mathrm{OTf})_{2}$ as the electrolyte (Figure $\mathbf{S 5}$ and S6). But instead of $\mathrm{Zn}_{4} \mathrm{SO}_{4}(\mathrm{OH})_{6} \cdot 5 \mathrm{H}_{2} \mathrm{O}$, a triflate containing $\mathrm{LDH}$ forms, apparent from the analogous set of diffraction peaks at lower angles, indicating a preferential proton intercalation mechanism for the oxides irrespective of the electrolyte (with a mildly acidic $\mathrm{pH}$ ). To the best of our knowledge, this is the first time the formation of a $\mathrm{LDH}$ phase is noted for the triflate anion. The respective XRD peaks of the triflate $\mathrm{LDH}$ correspond to an interlayer (zinc hydroxide layers) spacing of $13.7 \AA$ compared to $11.0 \AA^{24}$ for the sulfate containing LDH. Although the larger ionic radius of the triflate anion ( $2.75 \AA^{25}$ compared to $2.52 \AA^{26}$ for sulfate) alone cannot explain the large difference in the basal plane distance, it is quite plausible when the influence of composition and water content at the interlayer space is considered. ${ }^{27}$ Nevertheless, the determination of its exact structure and composition require further analysis. The lower intensity of the triflate LDH peaks may stem from its poor crystallinity due to the larger size and anisotropic molecular structure of the triflate anion.

The layered non-oxide - $\mathrm{VS}_{2}$ displays an expansion of the interlayer distance by about $0.12 \AA$ upon discharge, which almost reverts to the initial value on charge (Figure 2a and b). In contrast to the layered $\mathrm{V}_{3} \mathrm{O}_{7} \cdot \mathrm{H}_{2} \mathrm{O}$, the bonding in $\mathrm{VS}_{2}$ is predominantly covalent in nature, so there is no screening effect of zinc intercalation that could lead to contraction. Thus, the relatively smaller interlayer spacing in $\mathrm{VS}_{2}$ expands to accommodate the intercalating cations. In the case of $\mathrm{ZnHCF}$, the diffraction peak positions move only slightly upon cycling, however their relative intensity varied strongly, which agrees well with ex-situ measurements reported in literature (Figure 2c and d). ${ }^{17}$ Just as for the oxides, no obvious phase transformation is apparent with both non-oxides. However, in a stark contrast to the oxides, the electrochemical discharge of the non-oxides does not result in the $\mathrm{LDH}$ phase, suggesting a fundamental difference in their charge storage mechanism, which is discussed further in the next section. 

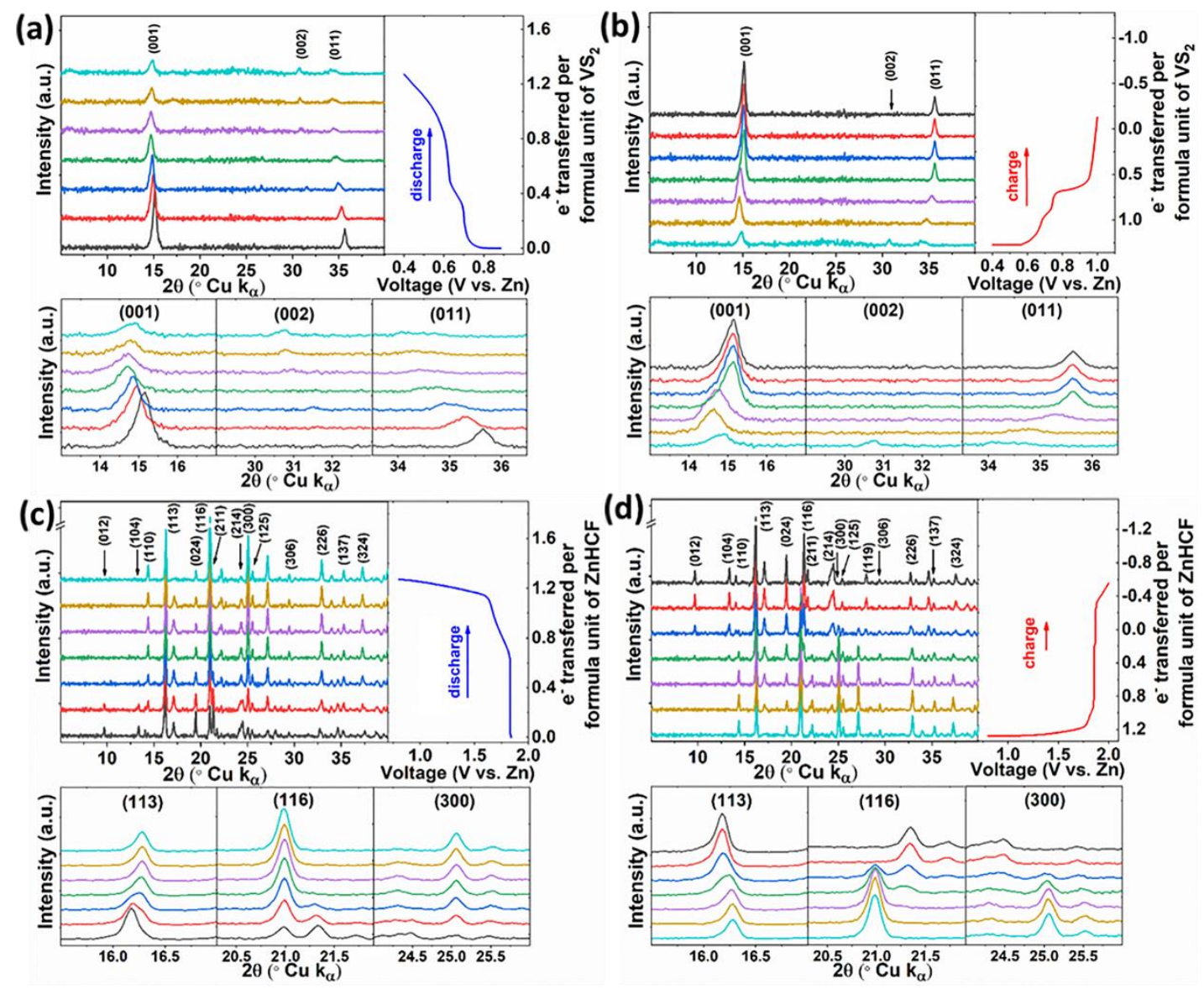

Figure 2. The Operando XRD study of a $\mathrm{VS}_{2}\left|\mathrm{ZnSO} \mathrm{Xn}_{4}\right| \mathrm{Zn}$ cell (a and b) and a $\mathrm{Zn}_{3}\left[\mathrm{Fe}(\mathrm{CN})_{6}\right]_{2}\left|\mathrm{ZnSO} \mathrm{Zn}_{4}\right| \mathrm{Zn}$ cell (c and d) at a (dis-)charge rate of C/5. Upper panel: XRD patterns (left) at different depths of discharge (a and $\mathrm{c}$ ) and charge (b and d) along with the voltage-electron capacity profile (right). Lower panel: magnification of the main XRD plot.

Nature of electrochemical charge storage mechanism of oxides vs. non-oxide host materials in AZBs. To probe the nature of cation intercalation process further, energy-dispersive X-ray spectroscopy (EDX) was used to identify the composition of the discharged electrodes, while any possible morphological changes upon discharge were investigated by TEM imaging. Figures 3ae show the STEM image of a discharged $\alpha-\mathrm{MnO}_{2}$ cathode and the respective EDX overlays for $\mathrm{Mn}, \mathrm{Zn}$ and S. Surprisingly, no significant amount of zincAZB is detected within the $\alpha-\mathrm{MnO}_{2-}$ nanorods. Whereas, a strong accumulation of zinc and sulfur is evident in a secondary phase around and in between the nanorods, corresponding to the $\mathrm{LDH}-\mathrm{Zn}_{4} \mathrm{SO}_{4}(\mathrm{OH})_{6} \cdot 5 \mathrm{H}_{2} \mathrm{O}$ observed in operando XRD. The retention of the initial nanorod morphology of $\alpha-\mathrm{MnO}_{2}$ (Figure $3 \mathbf{b}$ and Figure S2a) after discharge is clearly evident. So far, following three electrochemical charge storage mechanisms have been reported in literature for $\alpha-\mathrm{MnO}_{2}$ (see equations in SI) : (i) Zinc 
ion intercalation into $\alpha-\mathrm{MnO}_{2}$ with concomitant conversion to $\mathrm{ZnMn}_{2} \mathrm{O}_{4}{ }^{9}{ }^{9}$ (ii) reduction of $\alpha-\mathrm{MnO}_{2}$ followed by its reversible disproportionation and dissolution into the electrolyte as $\mathrm{Mn}^{2+} ;{ }^{22}$ and (iii) proton intercalation and the resultant conversion to $\mathrm{MnOOH} .{ }^{19,28}$ The first mechanism can be ruled out since it doesn't explain the LDH precipitation during discharge. More importantly, the EDS analysis of discharged $\alpha-\mathrm{MnO}_{2}$ could not show any zinc in the host material and the formation of $\mathrm{ZnMn}_{2} \mathrm{O}_{4}$ could not be confirmed by XRD (Figure S7). In contrast, the reduction-dissolution route can explain the $\mathrm{LDH}$ precipitation, as it results in the release of $\mathrm{OH}^{-}$into the electrolyte. However, this route would also lead to dissolution of half of the $\alpha-\mathrm{MnO}_{2}$ from the cathode (based on the observed/reported capacity), strongly affecting the morphology of the $\alpha-\mathrm{MnO}_{2}$ nanorods, which we do not observe. Moreover, the uniform shift of the $\alpha-\mathrm{MnO}_{2}$ diffraction peaks during cycling is also unexplainable by this mechanism. Not to mention that the electrochemically formed/deposited $\alpha-\mathrm{MnO}_{2}$ upon charge (from $\mathrm{Mn}^{2+}$ and $\mathrm{OH}^{-}$) is expected to display a different morphology/dimension than the initial nanorods, unlike the case here. Proton intercalation into $\alpha$ $\mathrm{MnO}_{2}$ can explain the observed lattice expansion, the retention of morphology, and the LDH precipitation during discharge; the last one is caused by an increase of the electrolyte $\mathrm{pH}$ due to the depletion of protons. Yet, operando XRD showed no phase transition of $\alpha-\mathrm{MnO}_{2}$, thus demonstrating that the conversion to $\mathrm{MnOOH}$ does not take place (Figure S7). We therefore propose that a solid-solution type proton intercalation, without any structural transformation, is responsible for the electrochemical charge storage in $\alpha-\mathrm{MnO}_{2}$ and the corresponding electrochemical reaction can be written as: $\mathrm{MnO}_{2}+\mathrm{H}^{+}+e^{-} \rightleftharpoons \mathrm{HnOO}_{2}$.

In contrast to $\alpha-\mathrm{MnO}_{2}$, EDX analysis of the discharged $\mathrm{V}_{3} \mathrm{O}_{7} \cdot \mathrm{H}_{2} \mathrm{O}$ showed a significant zinc concentration within the nano-belts (Figure 3f-i). Yet, the quantification of the zinc content revealed a composition of $\mathrm{Zn}_{0.6} \mathrm{~V}_{3} \mathrm{O}_{7} \cdot \mathrm{H}_{2} \mathrm{O}$ (Figure S8), which is much lower than the expected value of more than $2 \mathrm{Zn}$ per formula unit, based on the observed capacity. EDX mapping of zinc and sulfur further confirmed the formation of $\mathrm{Zn}_{4} \mathrm{SO}_{4}(\mathrm{OH})_{6} \cdot 5 \mathrm{H}_{2} \mathrm{O}$ (Figure 3i, encircled), as evidenced by operando XRD. Therefore, based on the voltage profile with two plateaus and the distinct structural changes in the two regions, observed in the operando XRD study, we can propose two separate charge storage mechanism for $\mathrm{V}_{3} \mathrm{O}_{7} \cdot \mathrm{H}_{2} \mathrm{O}$. Formation of only small amount of $\mathrm{LDH}$ precipitate in the first regime (as indicated by weak $\mathrm{LDH}$ peak intensities above $0.75 \mathrm{~V}$ ), and the close correlation of the observed capacity in this regime with the overall zinc content of the discharged electrode implies zinc intercalation being the dominant process in this segment. 
The second regime possesses multiple resemblances to the proton intercalation into $\alpha-\mathrm{MnO}_{2}$ such as the precipitation of $\mathrm{Zn}_{4} \mathrm{SO}_{4}(\mathrm{OH})_{6} \cdot 5 \mathrm{H}_{2} \mathrm{O}$ and the lattice expansion due to the intercalation of hydronium ions. For $\mathrm{VS}_{2}$, EDX mapping of $\mathrm{V}, \mathrm{Zn}$ and $\mathrm{S}$ shows a clear correlation between the distribution of $\mathrm{Zn}$ and $\mathrm{V}$, while no second phase, containing $\mathrm{Zn}$ and $\mathrm{S}$ in the absence of $\mathrm{V}$, could be found (Figure $\mathbf{3 j}-\mathbf{m})$.

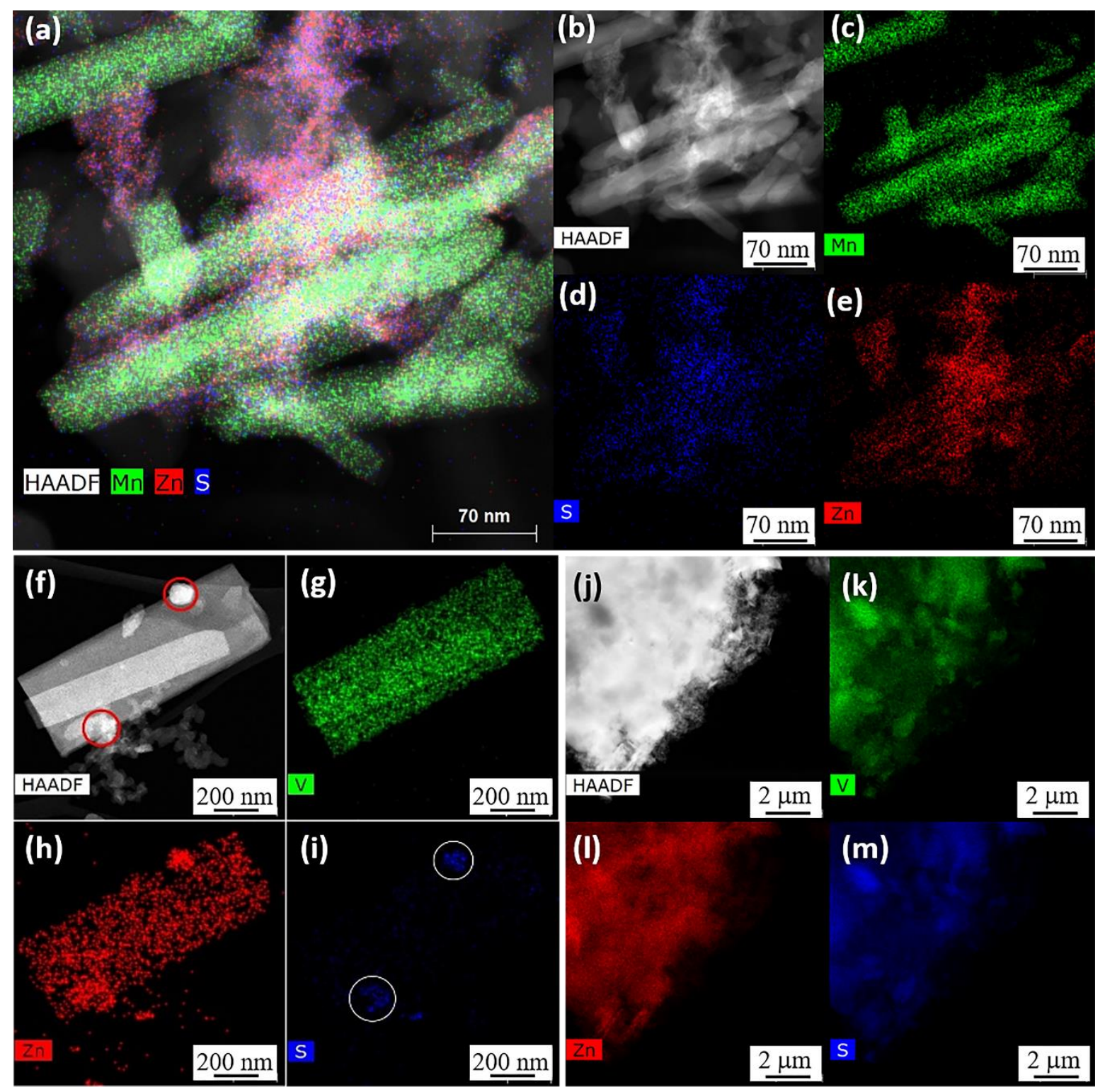

Figure 3. (a) HAADF STEM image of $\alpha-\mathrm{MnO}_{2}$ fibers after full discharge in $1 \mathrm{M} \mathrm{ZnSO}-\mathrm{H}_{2} \mathrm{O}$ electrolyte with EDX overlays of Mn, Zn and S. (b) HAADF STEM image and (c)-(e) individual EDX mapping of $\mathrm{Mn}, \mathrm{S}$ and $\mathrm{Zn}$. (f) HAADF STEM image and (g)-(i) EDX maps of V, Zn, and $\mathrm{S}$ of $\mathrm{V}_{3} \mathrm{O}_{7} \cdot \mathrm{H}_{2} \mathrm{O}$ nanorods after full discharge in a $1 \mathrm{M} \mathrm{ZnSO}_{4}$ electrolyte. Encircled areas in (f) and (i) indicate the $\mathrm{Zn}_{4} \mathrm{SO}_{4}(\mathrm{OH})_{6} \cdot 5 \mathrm{H}_{2} \mathrm{O}$ precipitate which formed during discharge. (j) HAADF STEM image and (k-m) EDS maps of V, Zn and S of a $\mathrm{VS}_{2}$ cathode after full discharge using a $1 \mathrm{M} \mathrm{ZnSO}_{4}$ electrolyte. 
Large area composition analysis by EDX in SEM revealed a $\mathrm{Zn} / \mathrm{S}$ ratio of $\sim 4 / 1$ for both discharged $\alpha-\mathrm{MnO}_{2}$ and $\mathrm{V}_{3} \mathrm{O}_{7} \cdot \mathrm{H}_{2} \mathrm{O}$ electrodes, in perfect correlation with the composition of the LDH precipitate, which appears as thin flakes blanketing discharged electrodes completely (Figure S9a and b). The very different morphology (or, rather loss of flake morphology) of the $\mathrm{LDH}$, observed under TEM, can be blamed on the sample preparation involving strong ultrasonication of the discharged electrode materials in isopropanol. In agreement with the operando XRD analysis, no LDH flakes were observed on the discharged $\mathrm{VS}_{2}$ and $\mathrm{ZnHCF}$ electrodes under SEM (Figure S9c and d), while EDX based $\mathrm{Zn} / \mathrm{S}$ and $\mathrm{Zn} / \mathrm{M}(\mathrm{M}=\mathrm{V} / \mathrm{Fe})$ ratios conform well with an exclusive zinc intercalation mechanism. A reversible $\mathrm{Zn}^{2+}$ deintercalation from $\mathrm{VS}_{2}$ and $\mathrm{ZnHCF}$ electrodes was further confirmed by EDX analysis of the charged electrode (Figure S9e and f).

The concentration of zinc ions in the electrolyte being more than 1000-fold higher than the concentration of protons, the prevailing proton intercalation mechanism for oxides seems unusual. Structurally, the two tunneled $\left(\alpha-\mathrm{MnO}_{2}, \mathrm{Zn}_{3}\left[\mathrm{Fe}(\mathrm{CN})_{6}\right]_{2}\right)$ and the two layered $\left(\mathrm{V}_{3} \mathrm{O}_{7} \cdot \mathrm{H}_{2} \mathrm{O}\right.$ and $\left.\mathrm{VS}_{2}\right)$ host materials resemble each other closely. The tunnel diameter of the former two ( $\sim 5 \AA$ and $\sim 4.9$ $\AA$, respectively) and the interlayer distance of the latter ( $\sim 3 \AA$ and $\sim 2.9 \AA$, respectively) two are almost identical. Clearly, host structure type - hence, solid-state diffusion behavior - does not seem to offer an explanation. Furthermore, the operational voltage windows of these materials do not exhibit any correlation of zinc/proton intercalation with redox potential. Thus, the charge transfer reaction at the electrode-electrolyte interface, ${ }^{29}$ which is known to govern the kinetics of ion intercalation beside solid-state diffusion, must be the key. Interestingly, chemical structure and functionality of the electrode surface can influence the desolvation of the ions at the interface, i.e. the charge transfer resistance. ${ }^{30}$ While the zeta-potential, which reflects the nature of surface Coulomb charge, may have a link to the interfacial charge transfer, the zeta-potentials of $\alpha-\mathrm{MnO}_{2}$, $\mathrm{V}_{3} \mathrm{O}_{7} \cdot \mathrm{H}_{2} \mathrm{O}, \mathrm{VS}_{2}$, and $\mathrm{Zn}_{3}\left[\mathrm{Fe}(\mathrm{CN})_{6}\right]_{2}$ in $1 \mathrm{M} \mathrm{ZnSO}_{4}$ showed no clear trend (Figure S10). Typically, in aqueous media, hydroxyl ions and water molecules coordinate the unsaturated surface cations of inorganic materials. For hydrophilic oxides, this effect is likely enhanced through the formation of hydrogen bonds with the neighboring oxygen atoms on the host surface. It has been shown that the presence of such a solid/liquid coordination environment ("Janus surface") can facilitate the desolvation of ionic species from the electrolyte. ${ }^{30}$ While the oxide ions of the host and the hydroxyl ions/water molecules coordinating the surface can stabilize the protons in close proximity 
to the electrode surface by hydrogen bonding and facilitate proton intercalation, the same is not feasible for the strongly solvated zinc ions. For non-oxides, there are no oxygen in the host lattice to enable the hydrogen bonding at the electrode interface, which explains the absence of proton intercalation. We therefore propose that the hydroxyl/water terminated oxide electrode interface preferentially aids in the desolvation of protons and their intercalation. A preliminary molecular dynamics simulation shed further light on this aspect as discussed below.

Computational insight into $\mathrm{H}^{+}$vs. $\mathrm{Zn}^{2+}$ intercalation in $\mathrm{V}_{3} \mathrm{O}_{7} . \mathrm{H}_{2} \mathrm{O}$. In order to probe the kinetic and thermodynamic driving forces behind the preferential proton intercalation in oxides, molecular dynamics (MD) simulations together with density functional theory (DFT) calculations were performed on $\mathrm{V}_{3} \mathrm{O}_{7} \cdot \mathrm{H}_{2} \mathrm{O}$. The selection of $\mathrm{V}_{3} \mathrm{O}_{7} \cdot \mathrm{H}_{2} \mathrm{O}$ as the host for this study was motivated by its simple layered structure with interlayer space for $\mathrm{Zn}^{2+} / \mathrm{H}^{+}$intercalation. Starting from the initial system models were constructed introducing $\mathrm{Zn}^{2+}$ in the interlayer space - corresponding to $\mathrm{ZnV}_{3} \mathrm{O}_{7} \cdot \mathrm{H}_{2} \mathrm{O}$ system (see experimental section and SI for details), which were equilibrated at 300 $\mathrm{K}$. We note that all our simulations are performed at the potential of zero charge. At this potential, the energetics of the ion intercalation could be easily assessed. Although the Zn-O bond length distributions agree well with experiments and recent molecular dynamics simulations, $\mathrm{Zn}^{2+}$ at equilibrium is found to be more stable in aqueous solution and extra energy is required in order to insert the $\mathrm{Zn}$ in the vanadium oxide host (Figure S11). Note that the calculations were performed for a zinc composition that is higher than the fraction of $\mathrm{Zn}$ (0.6 per formula unit) we could intercalate under galvanostatic condition. $\mathrm{H}^{+}$is found to be stable inside the host by about $0.8 \mathrm{eV}$ than in the solution, revealing the thermodynamic origin of the favored proton intercalation in the oxide host. Moreover, MD simulations showed that the presence of $\mathrm{H}^{+}$in the solution leads to a surface reconstruction involving the hydroxyl groups at the $\mathrm{V}_{3} \mathrm{O}_{7} \cdot \mathrm{H}_{2} \mathrm{O}$ /water interface (Figure 4) as speculated in the previous section. First, the proton is spontaneously adsorbed on a hydroxyl site at the interface leading to the formation of an adsorbed water molecule. Then, two adjacent adsorbed hydroxyls transform into a $\mathrm{HOH}$ complex and a proton is released into the water layer. Such a surface reconstruction mechanism would stabilize the $\mathrm{H}^{+}$at the electrode/electrolyte interface and facilitate the proton transfer across it. 

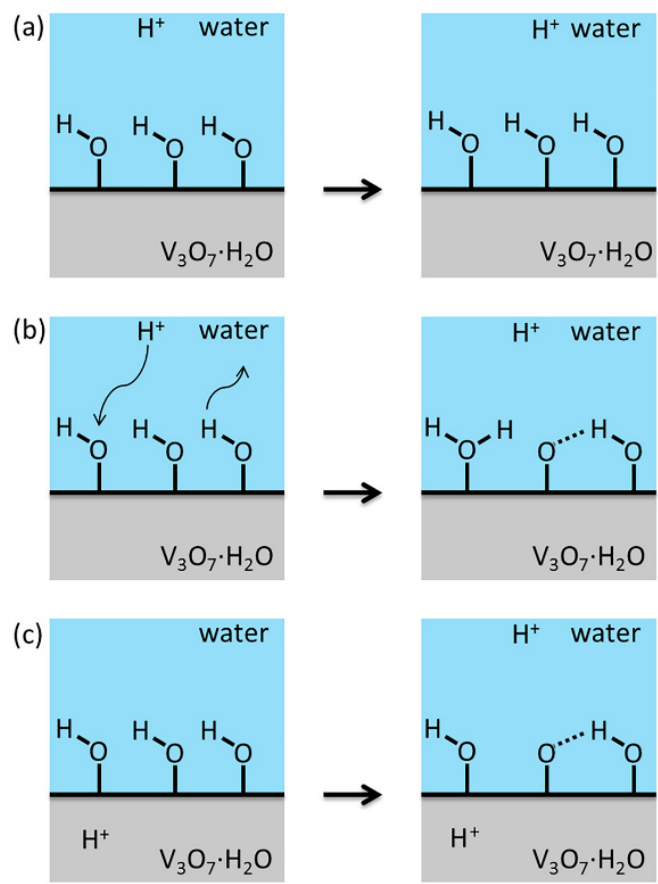

Figure 4. Sketch of the surface reconstruction in the $\mathrm{ZnV}_{3} \mathrm{O}_{7} \cdot \mathrm{H}_{2} \mathrm{O} /$ water system. (a) Model $\mathrm{H} 1$, in which the proton is constrained to stay in liquid water; no surface reconstruction is observed. (b) Model H2, in which no constraint is applied and surface reconstruction occurs. (c) Model H3 surface reconstruction with the proton inserted inside the oxide host.

\section{Evolution of the electrolyte pH and the consequences of LDH precipitation with oxide hosts.}

Since intercalating protons are consumed from the electrolyte, the $\mathrm{pH}$ of the electrolyte rises continuously during electrochemical discharge. Theoretically, the number of protons intercalated during the discharge of $\alpha-\mathrm{MnO}_{2}$ (according to the capacity exhibited by $\alpha-\mathrm{MnO}_{2}$ ) would result in an increase of the electrolyte $\mathrm{pH}$ from 4 to 13.76 (see Table S1 for details). However, depletion of protons in the electrolyte would impede the proton intercalation process and limiting the obtainable capacity. But that does not seem to happen, as increase of the electrolyte $\mathrm{pH}$ beyond a threshold value triggers $\mathrm{LDH}$ precipitation with both $1 \mathrm{M} \mathrm{ZnSO}_{4}$ and $\left.2 \mathrm{M} \mathrm{Zn(OTf}\right)_{2}$ electrolytes. The critical $\mathrm{pH}$ values of precipitation were identified to be $\sim 5.74$ for the sulfate LDH and $\sim 5.2$ for the triflate LDH by ex situ titration of the respective electrolytes with dilute sodium hydroxide solution. LDH precipitation buffers the electrolyte $\mathrm{pH}$ at a slightly acidic value, allowing the continuation of the proton intercalation. Thus, LDH formation is crucial for the proton intercalation mechanism to sustain, which is the key for excellent performance of $\alpha-\mathrm{MnO}_{2}$ as a cathode host in AZBs. 
An in-situ $\mathrm{pH}$ measurement during the cycling of a $\alpha-\mathrm{MnO}_{2}\left|\mathrm{ZnSO} \mathrm{S}_{4}\right| \mathrm{Zn}$ cell confirmed the effect of the proton intercalation and the buffering by $\mathrm{LDH}$ precipitation on the $\mathrm{pH}$ of the electrolyte (Figure S12). During the first discharge, the $\mathrm{pH}$ of the bulk electrolyte rose slowly from 4.1 to 5 , which increased up to the expected equilibrium value of $\sim 5.7$ upon holding the discharged battery at OCV. This delayed increase of the bulk $\mathrm{pH}$ can be explained by a very slow $\mathrm{pH}$ equilibration process (in the absence of convection), leading to the build-up of a gradient with the $\mathrm{pH}$ decreasing from the cathode interface, where the precipitation takes place, to the bulk of the electrolyte leveling off over time (Figure 5a-c). The significance of LDH precipitation for the discharge reaction could be further probed by using metal-sulfate salt electrolytes that would not form the LDH precipitate $\left(\mathrm{Li}_{2} \mathrm{SO}_{4}\right)$ or only do so at a much higher $\mathrm{pH}\left(10\right.$ for $\left.\mathrm{MgSO}_{4}\right)$. For these electrolytes, only a fraction of the theoretical discharge capacity of $\alpha-\mathrm{MnO}_{2}(\sim 30 \mathrm{mAh} / \mathrm{g}$ compared to $308 \mathrm{mAh} / \mathrm{g}$ ) is delivered (Figure S13), which is yet more than expected for proton intercalation in the absence of buffering. However, EDX analysis revealed partial intercalation of $\mathrm{Mg}$ ions being responsible for the exhibited capacity with the $\mathrm{MgSO}_{4}$ electrolyte (note: $\mathrm{Li}$ is not detectable with standard EDX) (Figure S14).

During charge, the reversal of the electrochemical reactions results in the deintercalation of protons from the cathode. This causes the LDH to dissolve, either by direct recombination of the ejected protons with $\mathrm{LDH}$ ( or $\mathrm{OH}^{-}$of $\mathrm{LDH}$ ), present on and around the $\alpha-\mathrm{MnO}_{2}$ nanorods, or due to the decrease of the local $\mathrm{pH}$ at the electrode interface (Figure 5d). Analogous to the case of discharge without LDH precipitation, in absence of the precipitate at the cathode, the local (electrode interface) $\mathrm{pH}$ is expected to drop drastically upon charging, hindering further proton deintercalation (Figure 5f). Thus, the presence of the LDH is also critical for the rechargeability of the cell. The complete deintercalation of protons would theoretically lead to the total dissolution of the $\mathrm{LDH}$ and the decrease of the electrolyte $\mathrm{pH}$ to its initial value of 4.14. However, the retention of a fraction $(0.017 \%)$ of the total number of protons intercalated during discharge is enough to keep the equilibrium $\mathrm{pH}$ of the electrolyte at 5.74 (Table S1). Indeed, the $\mathrm{pH}$ value was found to stagnate only during the first recharge, before continuing to rise towards the equilibrium during the second discharge (Figure S12). Given the incomplete reversibility of the proton (de)intercalation, the bulk electrolyte $\mathrm{pH}$ is therefore expected to increase monotonously to the equilibrium value in the first cycle and then to remain unchanged during further cycling. 


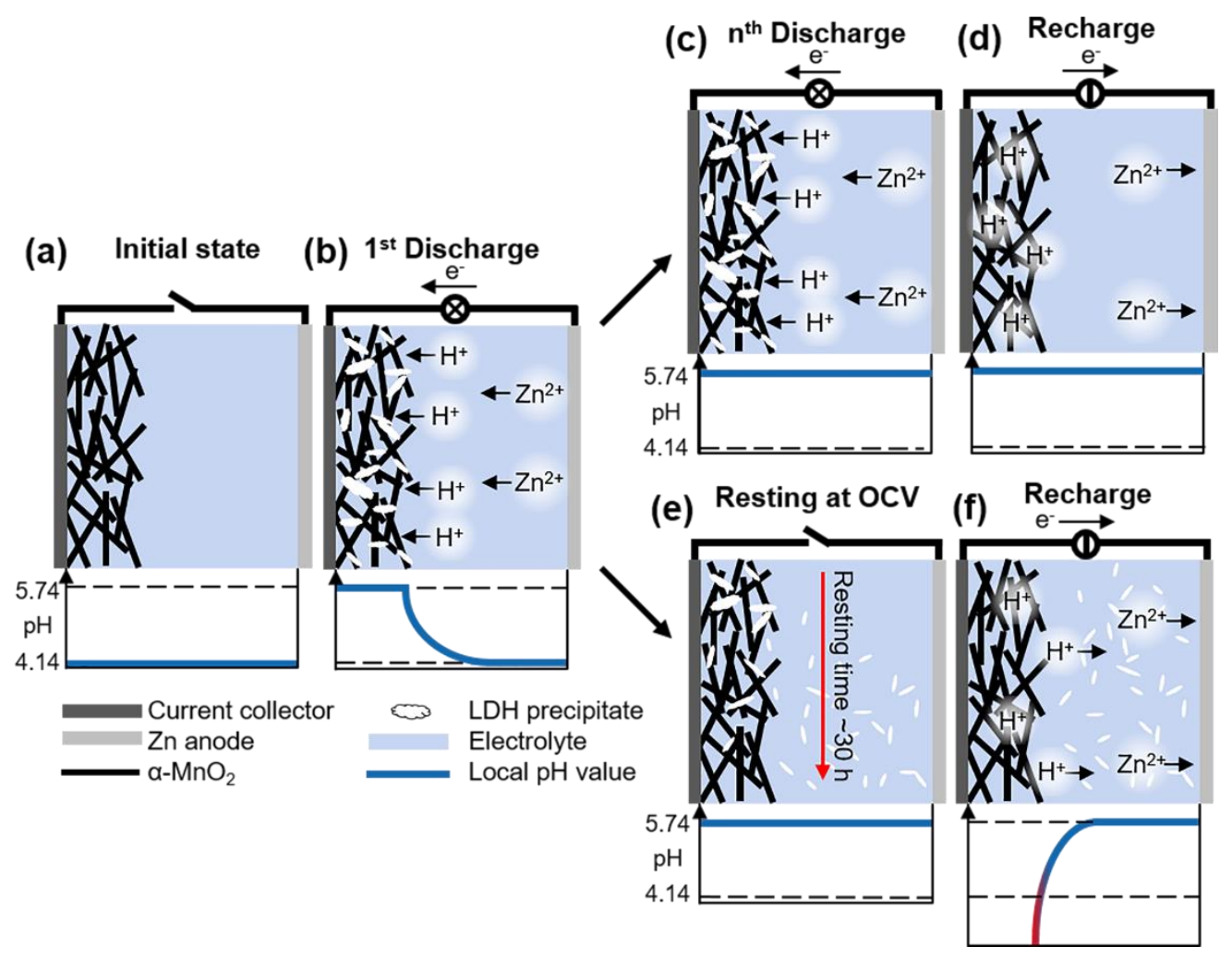

Figure 5. Schematic illustration of the $\mathrm{LDH}$ precipitate formation and $\mathrm{pH}$ evolution of the $\alpha-\mathrm{MnO}_{2} \mid \mathrm{Zn}$ $\mathrm{SO}_{4} \mid \mathrm{Zn}$ cell. (a) At the initial state, the $\mathrm{pH}$ value of the electrolyte corresponds to that of $1 \mathrm{M} \mathrm{ZnSO}_{4}$, i.e., $\mathrm{pH}$ 4.14. (b) During $\mathbf{1}^{\text {st }}$ discharge, $\mathrm{H}^{+}$intercalation into $\alpha-\mathrm{MnO}_{2}$ increases the $\mathrm{pH}$ locally at the cathode interface until the precipitation of the $\mathrm{Zn}_{4} \mathrm{SO}_{4}(\mathrm{OH})_{6} \cdot 5 \mathrm{H}_{2} \mathrm{O} \mathrm{LDH}$ buffers the $\mathrm{pH}$, resulting in a pH gradient, which slowly equilibrates to the precipitation $\mathrm{pH}$ value of 5.74. (c) After several cycles (considerably sufficient time), the $\mathrm{pH}$ of the electrolyte reaches the equilibrium $\mathrm{pH}$ of the $\mathrm{LDH}$ precipitation. (d) Upon recharge, the ejecting protons dissolve the $\mathrm{LDH}$, but the imperfect reversibility of the proton intercalation keeps the equilibrium $\mathrm{pH}$ of the electrolyte constant at 5.74. (e) Prolonged resting of the discharged cell at the OCV leads to the swelling of the LDH and its subsequent delamination and detachment from the cathode, while the $\mathrm{pH}$ of the electrolyte rises to (and stabilizes at) the equilibrium $\mathrm{pH}$ value of 5.74. (f) During subsequent recharge, the de-intercalating protons cause a drastic $\mathrm{pH}$ drop at the interface (due to the absence of the LDH precipitate as a pH-buffer), hindering further progression of the proton deintercalation and thus kinetically limiting the rechargeability of the battery.

To investigate the stability of the LDH precipitate at the cathode, an operando XRD study of the $\alpha-\mathrm{MnO}_{2}|\mathrm{ZnSO} 4| \mathrm{Zn}$ cell was conducted, in which the fully discharged cell was held at the OCV for prolonged time (Figure 6a). The OCV remained steady at around $1.45 \mathrm{~V}$ during the first $15 \mathrm{~h}$ of the rest period, but dropped by about $100 \mathrm{mV}$ and later reverted to $\sim 1.45 \mathrm{~V}$ in the last $15 \mathrm{~h}$. Interestingly, the fluctuating OCV during the last half coincide with the decrease in X-ray intensities coming from precipitate. At the end of the $30 \mathrm{~h}$ rest period, the diffraction peaks of the 
precipitate disappeared. An axiomatic explanation of this observation would be the dissolution of the sulfate LDH. Yet, the only way the dissolution is plausible is through deintercalation of protons during the OCV period. Since there is no current flow, the release of protons must be compensated by cations $\left(\mathrm{Zn}^{2+}\right)$ from the electrolyte, through ion exchange. The intercalation of zinc ions should however cause a stronger contraction of the lattice than observed here (Figure 6a), as not only the expansion due the proton intercalation (see above), but also an additional contraction due to the $\mathrm{Zn}^{2+}$ mediated electrostatic interaction is anticipated. Thus, we propose that the LDH precipitate physically detaches from the cathode surface through exfoliation of the lamellar structure, leading to the disappearance of its XRD signals. As there is no chemical bonding between the cathode surface and the precipitate, only electrostatic and van der Waals interactions ensure adhesion. Over prolonged resting in the electrolyte, the weekly bound metal hydroxide layers (by interlayer water and anions) in LDH can swell and exfoliate off into the electrolyte (Figure 5e). Upon subsequent charging of the rested cell at a $\mathrm{C} / 5$ rate, only $\sim 45 \%$ of the initial discharge capacity could be recovered $\left(\sim 120 \mathrm{mAh} \mathrm{g}^{-1}\right)$. Further cycling only lead to a marginal recovery of the capacity (Figure S15a and b). Whereas at a $\mathrm{C} / 25$, the recharge capacity doubled (Figure $\mathbf{6 b}$ ), which is only little
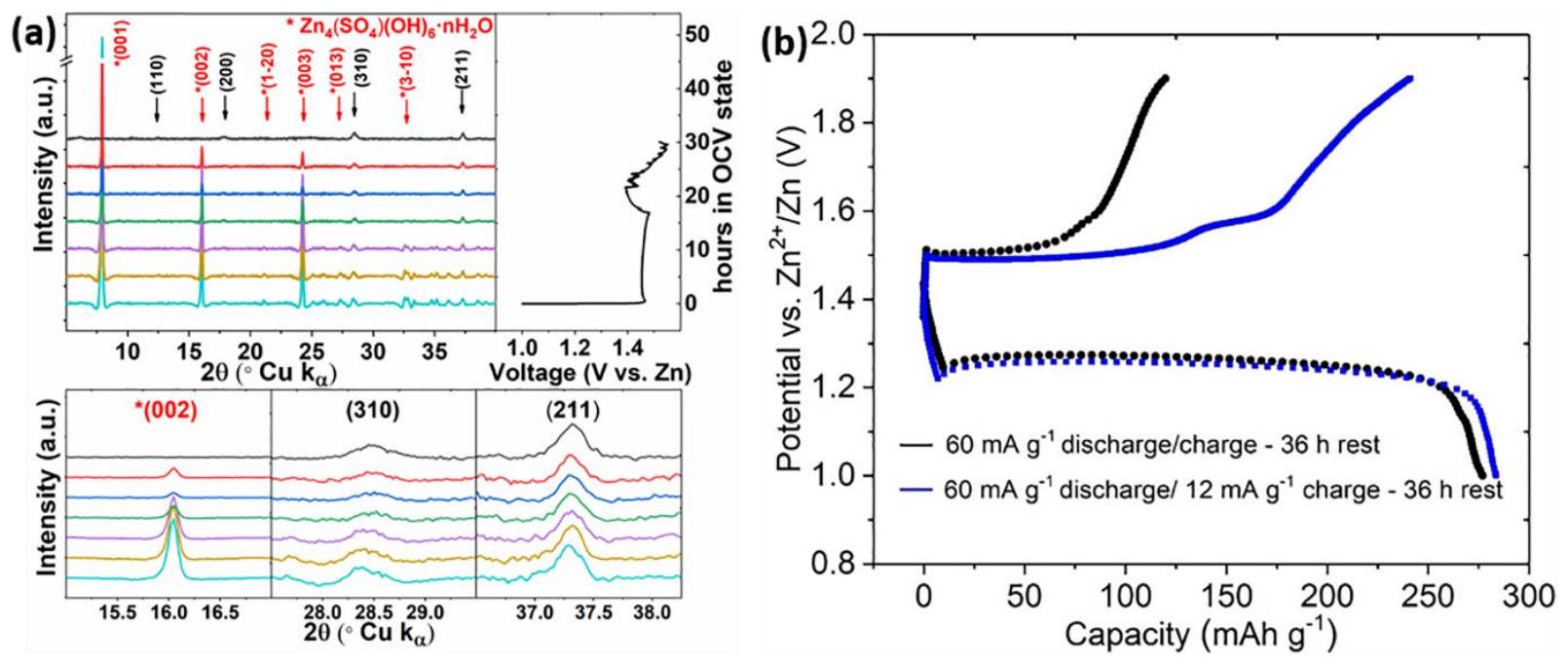

Figure 6. (a) The operando XRD study of a fully discharged $\alpha-\mathrm{MnO}_{2}\left|\mathrm{ZnSO}_{4}\right| \mathrm{Zn}$ battery (discharged at a current of $\sim 60 \mathrm{~mA} \mathrm{~g}^{-1}$ ) during resting for $30 \mathrm{~h}$ at the OCV. Upper plot: XRD pattern evolution (left) during the OCV period along with the voltage profile (right); bottom plot: magnifications of the main XRD plot. (b) Galvanostatic cycling of a $\alpha-\mathrm{MnO}_{2}\left|\mathrm{ZnSO}_{4}\right| \mathrm{Zn}$ battery with $36 \mathrm{~h}$ rest at the OCV after the first discharge at a current density of $60 \mathrm{~mA} \mathrm{~g}^{-1}(\sim \mathrm{C} / 5)$ and subsequent charging at $60 \mathrm{~mA} \mathrm{~g}^{-1}$ (C/5, black) and $12 \mathrm{~mA} \mathrm{~g}^{-1}$ (C/25, blue) exhibiting a capacity of $\sim 120 \mathrm{mAh} \mathrm{g}^{-1}$ and $\sim 240 \mathrm{mAh} \mathrm{g}^{-1}$, respectively. 
less than observed upon immediate recharging, i.e., without holding the battery at OCV for prolonged time. Similar results were obtained with a 2 M ZnOTf electrolyte, where even less than a third of the initial discharge capacity could be recovered after prolonged resting (Figure S15c and d). This limited, rate-dependent rechargeability of the cell agrees well with our explanations regarding the rechargeability in the absence of $\mathrm{LDH}$. Without the precipitate at the cathode interface, which could neutralize the ejecting protons, the $\mathrm{pH}$ at the interface drops sharply during charge, kinetically hindering further proton deintercalation (Figure 5f). Even though the $\mathrm{pH}$ of the bulk electrolyte would be near the precipitation $\mathrm{pH}$ of the $\mathrm{LDH}$, a proton concentration gradient would build up. The charge $\left(\mathrm{H}^{+}\right)$transfer reaction would therefore depend on the diffusion of protons and hydroxide ions from the precipitate. Upon further cycling, the newly formed precipitate during discharge would again stay at the cathode for the timescale of the cycling and would therefore be reversible upon recharge. As during each cycle a small part of the initial precipitate would additionally contribute to the recharge reaction, it could explain the gradual recovery of the capacity upon cycling after the resting period.

It's not only the poor rechargeability upon resting at OCV after discharge, LDH precipitation is also expected to cause large volume change at the cathode during cycling. For $\alpha-\mathrm{MnO}_{2}, \mathrm{LDH}$ precipitate weighs about $105 \%$ of the active cathode material after complete discharge, according to the number of protons intercalated, i.e., the capacity observed. Having a similar density (2700 $\left.\mathrm{kg} \mathrm{m}^{-3}\right)$ as the host material $\left(\sim 3000 \mathrm{~kg} \mathrm{~m}^{-3}\right)$, this translates to a volume expansion by $>100 \%$. The resultant mechanical stress within the cathode would be detrimental for long term cycling. Furthermore, the irreversibility of the precipitation may consume the electrolyte slowly, which makes the use of excess electrolyte necessary. This in addition to the volume expansion of the cathode during cycling would compromise the energy density of the whole cell.

\section{CONCLUSION}

The electrochemical charge storage mechanism in aqueous $\mathrm{Zn}$-ion batteries, which is generally believed to be reversible $\mathrm{Zn}^{2+}$ (de)intercalation into the positive host materials, is not exclusively true. Herein, through in-depth studies, we show that the oxides are dominant proton intercalation materials compared to the non-oxides that undergo exclusive $\mathrm{Zn}^{2+}$ storage. This intriguing difference stems from the surface hydroxyl groups on the oxides in aqueous electrolytes, which seem to facilitate proton transfer across the electrode interface. Considering that our study involved 
both tunneled and layered oxides, and most reported vanadium oxides (major positive host materials for AZBs) are layered, it is not unreasonable to assume that our observed charge storage mechanisms will apply to other AZB host materials as well. Reversible proton (de)intercalation in oxides leads to reversible formation/disappearance of the layered double hydroxide precipitate on the cathode surface, formed by the reaction of $\mathrm{OH}^{-}$(left behind after $\mathrm{H}^{+}$intercalation) with $\mathrm{Zn}^{2+}$ and electrolyte anion. The LDH precipitation perpetuates a buffering mechanism through continuous removal of $\mathrm{OH}^{-}$(during discharge) or $\mathrm{H}^{+}$(during charge), thereby maintaining the electrolyte $\mathrm{pH}$ at a mildly acidic value and sustain the $\mathrm{H}^{+}$(de)intercalation based charged storage mechanism. This buffering mechanism is crucial for the reversible and stable operation of the oxide host materials in AZBs. As we further witnessed, upon prolonged resting of the battery at the discharged state, the LDH precipitate tend to detach off the electrode surface, resulting in limited rechargeability, which can be a major hindrance to the practical application of oxide hosts in AZBs. Additionally, LDH precipitation/dissolution during battery discharge/charge will result in nearly $100 \%$ volume expansion at the cathode, posing further challenge to the practical operation of the battery. One solution to this conundrum may lie in tuning the surface functionality of the oxides so that the proton intercalation become disfavored.

\section{ASSOCIATED CONTENT}

Supporting information contains details of synthesis, in-situ $\mathrm{pH}$ measurement, XRD and SEM characterizations of the host materials under investigation, additional operando XRD and electrochemical results, SEM, TEM and EDX analysis of discharged/charged electrodes, Zetapotential measurements and in situ $\mathrm{pH}$ measurements

\section{ACKNOWLEDGEMENTS}

We thank the Swiss National Science Foundation (SNSF) for the financial support for this work through their Ambizione grant to D. K. We also acknowledge ScopeM (ETH Zurich) for providing the SEM facilities. AB and AP acknowledge the funding from the National Center of Competence in Research (NCCR) “Materials' Revolution: Computational Design and Discovery of Novel Materials (MARVEL)" of the Swiss National Science Foundation. 


\section{TOC GRAPHIC}

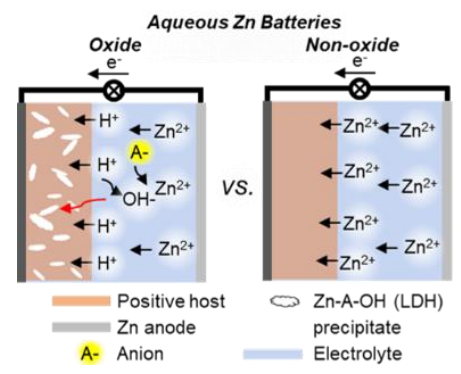

\section{REFERENCES}

(1) Chauhan, A.; Saini, R. P. A Review on Integrated Renewable Energy System Based Power Generation for Stand-Alone Applications: Configurations, Storage Options, Sizing Methodologies and Control. Renew. Sust. Energ. Rev. 2014, 38, 99-120.

(2) Luo, X.; Wang, J.; Dooner, M.; Clarke, J. Overview of Current Development in Electrical Energy Storage Technologies and the Application Potential in Power System Operation. Appl. Energy 2015, 137, 511-536.

(3) Kim, H.; Hong, J.; Park, K. Y.; Kim, H.; Kim, S. W.; Kang, K. Aqueous Rechargeable Li and Na Ion Batteries. Chem. Rev. 2014, 114, 11788 - 11827.

(4) Bin, D.; Wang, F.; Tamirat, A. G.; Suo, L.; Wang, Y.; Wang, C.; Xia, Y. Progress in Aqueous Rechargeable Sodium-Ion Batteries. Adv. Energy Mater. 2018, 8, 1703008.

(5) Guduru, R. K.; Icaza, J. C. A Brief Review on Multivalent Intercalation Batteries with Aqueous Electrolytes. Nanomaterials (Basel) 2016, 6, 41

(6) Zhang, X. G. Corrosion and Electrochemistry of Zinc. Springer Science \& Business Media 2013.

(7) Fang, G.; Zhou, J.; Pan, A.; Liang, S. Recent Advances in Aqueous Zinc-Ion Batteries. ACS Energy Lett. 2018, 3, 2480-2501.

(8) Rong, Z.; Malik, R.; Canepa, P.; Gautam, G-S.; Liu, M.; Jain, A.; Persson, K.; Ceder, G. Materials Design Rules for Multivalent Ion Mobility in Intercalation Structures. Chem. Mater. 2015, 27, 6016-6021.

(9) Xu, C.; Li, B.; Du, H.; Kang, F. Energetic Zinc Ion Chemistry: The Rechargeable Zinc Ion Battery. Angew. Chem. Int. Ed. 2012, 51, 933-935.

(10) Yuan, C.; Zhang, Y.; Pan, Y.; Liu, X.; Wang, G.; Cao, D. Investigation of The Intercalation of Polyvalent Cations $\left(\mathrm{Mg}^{2+}, \mathrm{Zn}^{2+}\right)$ into $\lambda-\mathrm{MnO}_{2}$ for Rechargeable Aqueous Battery. Electrochim. Acta 2014, 116, 404-412.

(11) Lee, J.; Ju, J. B.; Cho, W. I.; Cho, B. W.; Oh, S. H. Todorokite-type $\mathrm{MnO}_{2}$ as a Zinc-Ion Intercalating Material. Electrochim. Acta 2013, 112, 138-143.

(12) Kundu, D.; Hosseini Vajargah, S.; Wan, L.; Adams, B.; Prendergast, D.; Nazar, L. F. Aqueous vs. Nonaqueous Zn-Ion Batteries: Consequences of the Desolvation Penalty at the Interface. Energy Environ. Sci. 2018, 11, 881-892 
(13) Kundu, D.; Adams, B. D.; Duffort, V.; Vajargah, S. H.; Nazar, L. F. A High-Capacity and LongLife Aqueous Rechargeable Zinc Battery Using a Metal Oxide Intercalation Cathode. Nat. Energy 2016, $1,16119$.

(14) Alfaruqi, M. H.; Mathew, V.; Song, J.; Kim, S.; Islam, S.; Pham, D. T.; Jo, J.; Kim, S.; Baboo, J. P.; Xiu, J.; Lee, K-S.; Sun, Y-K.; Kim, J. Electrochemical Zinc Intercalation in Lithium Vanadium Oxide: a High-Capacity Zinc-Ion Battery Cathode. Chem. Mater. 2017, 29, 1684-1694.

(15) Xia, C.; Guo, J.; Lei, Y.; Liang, H.; Zhao, C.; Alshareef, H. N. Rechargeable Aqueous Zinc-Ion Battery Based on Porous Framework Zinc Pyrovanadate Intercalation Cathode. Adv. Mater. 2018, 30, 1705580.

(16) He, P.; Yan, M.; Zhang, G.; Sun, R.; Chen, L.; An, Q.; Mai, L. Layered VS 2 Nanosheet-Based Aqueous Zn Ion Battery Cathode. Adv. Energy Mater. 2017, 7, 1601920.

(17) Zhang, L.; Chen, L.; Zhou, X.; Liu, Z. Towards High-Voltage Aqueous Metal-Ion Batteries Beyond $1.5 \mathrm{~V}$ : the Zinc/Zinc Hexacyanoferrate System. Adv. Energy Mater. 2015, 5, 1400930.

(18) Trocoli, R.; Mantia, F. L. An Aqueous Zinc-Ion Battery Based on Copper Hexacyanoferrate. ChemSusChem 2015, 8, 481-485.

(19) Pan, H.; Shao. Y.; Yan, P.; Cheng, Y.; Han, K. S.; Nie, Z.; Wang, C.; Yang, J.; Li, X.; Bhattacharya, P.; Mueller, K. T.; Liu, J. Reversible Aqueous Zinc/Manganese Oxide Energy Storage from Conversion Reactions. Nat. Energy 2016, 1, 16039.

(20) Pasta, M; Wessells, C. D.; Liu, N.; Nelson, J.; McDowell, M. T.; Huggins. R. A.; Toney, M. F.; Cui, Y. Full Open-Framework Batteries for Stationary Energy Storage. Nat. Commun. 2014, 5, 3007

(21) Ni G, Han B, Li Q, Ji Z, Huang B, Zhou C. Instability of Zinc Hexacyanoferrate Electrode in an Aqueous Environment: Redox-Induced Phase Transition, Compound Dissolution, and Inhibition. ChemElectroChem 2016, 3, 798-804.

(22) Lee, B.; Seo, H. R.; Lee, H. R.; Yoon, C. S.; Kim, J. H.; Chung, K. Y.; Cho, B. W.; Oh, S. H. Critical Role of $\mathrm{pH}$ Evolution of Electrolyte in the Reaction Mechanism for Rechargeable Zinc Batteries. ChemSusChem 2016, 9, 2948-2956.

(23) Umek, P.; Korošec, R. C.; Gloter, A.; Pirnat, U. The Control of the Diameter and Length of $\alpha-\mathrm{MnO}_{2}$ Nanorods by Regulation of Reaction Parameters and their Thermogravimetric Properties. Mater. Res. Bull. 2011, 46, 278-284.

(24) Ohnishi, M.; Kusachi, I.; Kobayashi, S. Osakite, $\mathrm{Zn}_{4} \mathrm{SO}_{4}(\mathrm{OH})_{6} \cdot 5 \mathrm{H}_{2} \mathrm{O}$, A New Mineral Species From the Hirao Mine, Osaka, Japan. Can. Mineral. 2007, 45, 1511-1517

(25) Yamada, M.; Hagiwara, H.; Torigoe, H.; Matsumoto, N.; Kojima, M.; Dahan, F.; Tuchagues, J. P.; Re, N.; Iijima, S. A Variety of Spin-Crossover Behaviors Depending on the Counter Anion: TwoDimensional Complexes Constructed by NH...Cl- Hydrogen Bonds, [FeIIH3LMe]Cl.X (X = $\mathrm{PF}_{6}{ }^{-}$, $\mathrm{AsF}_{6}{ }^{-}, \mathrm{SbF}_{6}{ }^{-}, \mathrm{CF}_{3} \mathrm{SO}_{3}{ }^{-} ; \mathrm{H}_{3} \mathrm{~L}(\mathrm{Me})=$ Tris[2-\{[(2-methylimidazol-4yl)methylidene]amino \}ethyl]amine). Chemistry 2006, 12, 4536 - 4549.

(26) Marcus, Y. The Molar Volumes of Ions in Solution, part 7. Electrostriction and Hydration Numbers of Aqueous Polyatomic Anions at 25 Degrees C. J Phys. Chem. B 2014, 118, 2172-2175

(27) Evans, D. G.; Slade, R. C. T. Structural Aspects of Layered Double Hydroxides. In Layered Double Hydroxides. Structure and Bonding, vol. 119. Springer, Berlin, Heidelberg, 2005. 
(28) Sun, W.; Wang, F.; Hou, S.; Yang, C.; Fan, X.; Ma, Z.; Gao, T.; Han, F.; Hu, R.; Zhu, M.; Wang, C. $\mathrm{Zn} / \mathrm{MnO}_{2}$ Battery Chemistry With $\left.\mathrm{H}^{+}\right)$and $\mathrm{Zn}\left({ }^{2+}\right)$ Coinsertion. J. Am. Chem. Soc. 2017, 139, 97759778.

(29) Han, S. D.; Rajput, N. N.; Qu, X.; Pan, B.; He, M.; Ferrandon, M. S.; Liao, C.; Persson, K. A.; Burrell, A. K. Origin of Electrochemical, Structural, and Transport Properties in Nonaqueous Zinc Electrolytes. ACS Appl. Mater. Interfaces 2016, 8, 3021-3031.

(30) Zheng, J.; Hou, Y.; Duan, Y.; Song, X.; Wei, Y.; Liu, T.; Hu, J.; Guo, H.; Zhuo, Z.; Liu, L.; Chang, Z.; Wang, X.; Zherebetskyy, D.; Fang, Y.; Lin, Y.; Xu, K.; Wang, L. W.; Wu, Y.; Pan, F. Janus Solid-Liquid Interface Enabling Ultrahigh Charging and Discharging Rate for Advanced LithiumIon Batteries. Nano Lett. 2015, 15, 6102-6109. 